\title{
Ion Activities and Zinc Electrode Reactions in Calcium Chloride Solutions
}

\author{
TURID R. BREIVIK and TOR HURLEN
}

Department of Chemistry, University of Oslo, Blindern, Norway

The title subjects are studied in various pure and mixed aqueous solutions of zinc and calcium chlorides at $25^{\circ} \mathrm{C}$, but most extensively in slightly acidified $0.005 \mathrm{~m} \mathrm{ZnCl}_{2}+x \mathrm{~m} \mathrm{CaCl}_{2}$ for $x=0.2-$ 6.0.* In this solution series, the bare-ion activity coefficients rises strongly for $\mathrm{Ca}^{2+}$ and slightly for $\mathrm{Cl}^{-}$after a minimum at $x$ near 0.5 , whereas it strongly falls for $\mathrm{Zn}^{2+}$ due to complex formation with chloride ions. In the same solution seires, the $\mathrm{Zn} / \mathrm{Zn}$ (II) electrode appears to be kinetically controlled by the couple $\mathrm{Zn}\left(\mathrm{H}_{2} \mathrm{O}\right)_{4} \mathrm{Cl}_{2}^{-} / \mathrm{Zn}\left(\mathrm{H}_{2} \mathrm{O}\right)_{4} \mathrm{Cl}_{2}$ at $x$-values above 0.5 and by corresponding $\mathrm{Zn}(\mathrm{I}) / \mathrm{Zn}(\mathrm{II})$ couples of lower or no chloride content at lower $x$-values.

As briefly described in two previous contributions from our laboratory, ${ }^{1,2}$ the reactions of the $\mathrm{Zn} / \mathrm{Zn}$ (II) electrode in aqueous solution seem to occur in two consecutive steps of which the $\mathrm{Zn}(\mathrm{I}) / \mathrm{Zn}$ (II) electrontransfer step is the rate-determining one. Our studies moreover suggest that the electroactive $\mathrm{Zn}(\mathrm{I}) / \mathrm{Zn}(\mathrm{II})$ couple be mainly $\mathrm{Zn}\left(\mathrm{H}_{2} \mathrm{O}\right)_{6}^{+} / \mathrm{Zn}$ $\left(\mathrm{H}_{2} \mathrm{O}\right)_{6}^{2+}$ in sulfate ${ }^{2}$ and dilute chloride ${ }^{1}$ solutions and $\mathrm{Zn}\left(\mathrm{H}_{2} \mathrm{O}\right)_{4} \mathrm{Cl}_{2}^{-} / \mathrm{Zn}\left(\mathrm{H}_{2} \mathrm{O}\right)_{4} \mathrm{Cl}_{2}$ in more concentrated chloride solution, ${ }^{1}$ but the water and chloride activity ranges covered by these studies are rather small. The present work pursues this over considerably expanded activity ranges by extending the kinetic studies to a wide concentration range of zinc and calcium chlorides in aqueous solution at $25^{\circ} \mathrm{C}$.

A convenient scale for single-ion activities is introduced in Ref. 1, and its subsequent use is briefly summarized in Ref. 2 . The present work extends also such ion-activity studies to a wide concentration range $(0.2-6.0 \mathrm{~m})$ of calcium chloride in aqueous solution at $25^{\circ} \mathrm{C}$. This follows previous studies of such solutions with nickel (instead of zinc) chloride as a minority salt. ${ }^{3}$

\section{EXPERIMENTAL}

The experimental work comprises equilibrium potential measurements on saturated $\mathrm{Zn}(\mathrm{Hg}) / \mathrm{Zn}(\mathrm{II})$ and $\mathrm{Ag} / \mathrm{AgCl}$ electrodes $v$ s. SCE and kinetic polarization measurements on etched (in hot $4 \mathrm{M} \mathrm{HCl}$ ) high-purity $(99.999 \%$ ) zinc wire electrodes (exposed surface area near $0.3 \mathrm{~cm}^{2}$ ) in the three solution series:

$0.005 \mathrm{~m} \mathrm{ZnCl}_{2}+x \mathrm{~m} \mathrm{CaCl}_{2}$

$x \mathrm{~m} \mathrm{ZnCl}{ }_{2}$

$x \mathrm{~m} \mathrm{ZnCl} 2+(4-x) \mathrm{m} \mathrm{CaCl}_{2}$

with $x=0.2-6.0$ in (A) and (B) and $x=0.005-4.0$ in (C) and addition of hydrochloric acid to $\mathrm{pH}$ about 2.5 , all at $25^{\circ} \mathrm{C}$.

The solutions were prepared from p.a. quality salts and acid and twice distilled water, deoxygenated by purified and premoistened nitrogen, and kept under nitrogen atmosphere during the measurements. The measurements have been performed with techniques, equipment and procedures essentially as previously described. ${ }^{1-3}$ This includes capacity (purity) checking and ohmic drop correction by the slope and the gap of fast galvanostatic transients. ${ }^{2}$ The capacity of "good" zinc wire electrodes essentially was the same (near $55 \mu \mathrm{F} \mathrm{cm}^{-2}$ ) in the present chloride solutions as in previously studied sulfate solutions. ${ }^{2}$

* $1 \mathrm{~m}=1 \mathrm{~mol} \mathrm{~kg}^{-1}$. 


\section{ACTIVITY DATA}

The conventional mean molal activity coefficient $\left(\gamma_{ \pm}\right)$and the convenient single-ion ones $\left(\gamma_{2+}^{\prime}\right.$ and $\left.\gamma_{-}^{\prime}\right)$ for zinc(II) and chloride ions in the test solutions are given by (see Ref. 1):

$\gamma_{ \pm}=m^{\circ} m_{2+}^{-1 / 3} m_{-}^{-2 / 3} \exp \left\{(2 / 3) f\left[E_{2+}^{\prime}-E_{2+}^{\circ}-\right.\right.$ $\left.\left.\left(E_{-}^{\prime}-E_{-}^{0}\right)\right]\right\}$

$\gamma_{2+}^{\prime}=m^{\circ} m_{2+}^{-1} \exp \left[2 f\left(E_{2+}^{\prime}-\left(\phi_{\mathrm{t}}-\phi_{\mathrm{r}}\right)-E_{2+}^{\circ}+0.241\right)\right]$

$\gamma_{-}^{\prime}=m^{\circ} m_{-}^{-1} \exp \left[-f\left(E_{-}^{\prime}-\left(\phi_{\mathrm{t}}-\phi_{\mathrm{r}}\right)-E_{-}^{\circ}+0.241\right)\right]$

where $m^{\circ}$ is the standard molality $(1 \mathrm{~mol} / \mathrm{kg})$, $m_{2+}$ and $m_{-}$, respectively, are the zinc(II) and the chloride molality, $f$ means $F / R T, E_{2+}^{\prime}$ and $E_{-}^{\prime}$, respectively, are the apparent (including liquid junction) reversible $\mathrm{Zn} / \mathrm{Zn}(\mathrm{II})$ and $\mathrm{Ag} / \mathrm{AgCl}$ potentials in $\mathrm{V}(\mathrm{SCE}), E_{2+}^{\circ}$ and $E_{-}^{\circ}$ are the standard potentials of these electrodes in $\mathrm{V}(\mathrm{SHE}), \phi_{\mathrm{t}}-\phi_{\mathrm{r}}$ is the liquid-junction potential difference between test and reference (saturated $\mathrm{KCl}$ ) solution in $\mathrm{V}$, and $0.241 \mathrm{~V}(\mathrm{SHE})$ is the recommended value ${ }^{4}$ for $E^{\circ}\left(\mathrm{Hg} / \mathrm{Hg}_{2} \mathrm{Cl}_{2}\right)-f^{-1} \ln \left(a_{ \pm}(\mathrm{sat} . \mathrm{KCl}) / a^{\circ}\right)$, all at 25 ${ }^{\circ} \mathrm{C}$. These activity coefficients are bare-ion ones.

Table 1 presents the $E^{\prime}$ values measured and the $\gamma_{ \pm}$values hence obtained from (1) for zinc chloride in the solution series $(\mathrm{A})-(\mathrm{C})$, when $E^{\circ} / \mathrm{V}$ (SHE) values of 0.222 and -0.763 are used for $\mathrm{Ag} / \mathrm{AgCl}$ and $\mathrm{Zn} / \mathrm{Zn}(\mathrm{II}),{ }^{4-6}$ respectively. The values presently obtained for $\gamma_{ \pm}$of zinc chloride in essentially pure solutions of this salt, the solution series (B), check well with previously tabulated data. ${ }^{5}$ The authors are not aware of data for checking the present results in the mixed solutions of zinc and calcium chlorides, the solution series (A) and (C).

Table 2 presents $\phi_{t}-\phi_{\mathrm{r}}$ values estimated (from the Henderson equation ${ }^{7}$ and mobility data ${ }^{5}$ ) and $\gamma_{z}^{\prime}$ values hence obtained from (1), (2) and $\gamma_{2+}^{\prime}(\mathrm{Ca})=$ $\left[\gamma_{ \pm}\left(\mathrm{CaCl}_{2}\right)\right]^{3} /\left[\gamma_{-}^{\prime}(\mathrm{Cl})\right]^{2}$ for zinc, chloride and calcium ions in the solution series (A). Values of $\gamma_{ \pm}$for calcium chloride in pure $x \mathrm{~m}$ solutions of this salt ${ }^{5}$ have then been accepted for it in the corresponding solutions (A). Also values for the water activity $\left(a_{w}\right)$ of such pure calcium chloride solutions ${ }^{5}$ are reproduced in Table 2 and are presently accepted for the test solutions (A).

Fig. 1 compares the various activity coefficients in the solution series (A) with each other. It is there clearly shown how the mean-ion and cation activity coefficients of the minority salt $\left(\mathrm{ZnCl}_{2}\right)$ increasingly separate from those of the main salt $\left(\mathrm{CaCl}_{2}\right)$ with increasing salt concentration. This separation, which has no counterpart in corresponding $\mathrm{ZnSO}_{4}-$ $\mathrm{MgSO}_{4}$ solutions, ${ }^{2}$ naturally comes from a rather strong complexing of zinc(II) with chloride ions in the solutions. ${ }^{5,8,9}$ Although the present activity data show the formation of such complexes, they hardly reveal their composition and stability.

Table 1. $\mathrm{Zn} / \mathrm{Zn}$ (II) and $\mathrm{Ag} / \mathrm{AgCl}$ reversible potentials and mean molal bare-ion activity coefficient of $\mathrm{ZnCl}_{2}$ in various solutions at $25^{\circ} \mathrm{C}$. Potentials in $\mathrm{V}(\mathrm{SCE})$ including liquid junction.

\begin{tabular}{|c|c|c|c|c|c|c|c|}
\hline$x$ & 0.2 & 0.5 & 1 & 2 & 3 & 4 & 6 \\
\hline $\begin{array}{l}\text { In } 0 \\
E_{2+}^{\prime} \\
E_{-}^{\prime} \\
\gamma_{ \pm}\end{array}$ & $\begin{array}{c}\mathrm{ZnCl}_{2}+ \\
-1.090 \\
+0.014 \\
0.48\end{array}$ & $\begin{array}{c}\mathrm{CaCl}_{2} \\
-1.090 \\
-0.005 \\
0.43\end{array}$ & $\begin{array}{c}-1.091 \\
-0.021 \\
0.40\end{array}$ & $\begin{array}{c}-1.106 \\
-0.038 \\
0.27\end{array}$ & $\begin{array}{c}-1.118 \\
-0.049 \\
0.20\end{array}$ & $\begin{array}{c}-1.130 \\
-0.060 \\
0.16\end{array}$ & $\begin{array}{c}-1.127 \\
-0.074 \\
0.19\end{array}$ \\
\hline $\begin{array}{l}\text { In } x \\
E_{2+}^{\prime} \\
E_{-}^{\prime} \\
\gamma_{ \pm}\end{array}$ & $\begin{array}{c}\mathrm{Cl}_{2} \\
-1.040 \\
+0.019 \\
0.46\end{array}$ & $\begin{array}{c}-1.025 \\
+0.005 \\
0.39\end{array}$ & $\begin{array}{c}-1.010 \\
-0.002 \\
0.34\end{array}$ & $\begin{array}{c}-0.990 \\
-0.002 \\
0.29\end{array}$ & $\begin{array}{c}-0.972 \\
+0.001 \\
0.29\end{array}$ & $\begin{array}{c}-0.952 \\
+0.007 \\
0.31\end{array}$ & $\begin{array}{c}-0.911 \\
+0.021 \\
0.42\end{array}$ \\
\hline$x$ & 0.005 & 0.03 & 0.1 & 0.3 & 1 & 2 & 4 \\
\hline $\begin{array}{l}\text { In } x \\
E_{2+}^{\prime} \\
E_{-}^{\prime} \\
\gamma_{ \pm}\end{array}$ & $\begin{array}{c}\mathrm{Cl}_{2}+(4- \\
-1.130 \\
-0.060 \\
0.16\end{array}$ & $\begin{array}{c}\mathrm{CaCl}_{2} \\
-1.105 \\
-0.059 \\
0.17\end{array}$ & $\begin{array}{c}-1.088 \\
-0.057 \\
0.16\end{array}$ & $\begin{array}{c}-1.069 \\
-0.055 \\
0.18\end{array}$ & $\begin{array}{c}-1.034 \\
-0.041 \\
0.20\end{array}$ & $\begin{array}{c}-0.988 \\
-0.015 \\
0.27\end{array}$ & $\begin{array}{c}-0.952 \\
+0.007 \\
0.31\end{array}$ \\
\hline
\end{tabular}


Table 2. Liquid-junction $\left(\Delta \phi=\phi_{1}-\phi_{\mathrm{r}}\right)$, single-ion and water data for $0.005 \mathrm{~m} \mathrm{ZnCl}+x \mathrm{~m} \mathrm{CaCl}_{2}$ at $25{ }^{\circ} \mathrm{C}$ (see text).

\begin{tabular}{llllllll}
\hline$x$ & 0.2 & 0.5 & 1 & 2 & 3 & 4 & 6 \\
\hline$\Delta \phi / \mathrm{V}$ & 0.001 & 0.003 & 0.005 & 0.008 & 0.010 & 0.011 & 0.013 \\
$\gamma_{-}^{\prime}(\mathrm{Cl})$ & 0.70 & 0.65 & 0.65 & 0.71 & 0.79 & 0.95 & 1.18 \\
$\gamma_{2+}^{\prime}(\mathrm{Zn})$ & 0.23 & 0.20 & 0.15 & 0.038 & 0.013 & 0.0046 & 0.0050 \\
$\gamma_{2+}^{\prime}(\mathrm{Ca})$ & 0.22 & 0.21 & 0.30 & 0.99 & 5.2 & 28 & 985 \\
$a_{\mathrm{w}}$ & 0.991 & 0.976 & 0.945 & 0.862 & 0.749 & 0.624 & 0.392 \\
\hline
\end{tabular}

\section{KINETIC DATA}

The kinetic data of the present work apply to preetched zinc wire electrodes in solutions of series (A). In these calcium chloride solutions, the solid zinc electrode is found to behave somewhat as in magnesium sulfate solutions ${ }^{2}$ by showing a slightly unstable and stirring-dependent open-circuit potential (a little positive to the reversible $\mathrm{Zn} / \mathrm{Zn}$ (II) potential) and exhibiting charge-transfer controlled anodic and cathodic Tafel lines with $E / \ln i$ slopes of typically $2 R T / 3 F$ and $-2 R T / F$, respectively. The latter conforms with results also in potassium chloride solutions, ${ }^{1}$ and it agrees with the introductionally mentioned two-step mechanism of the

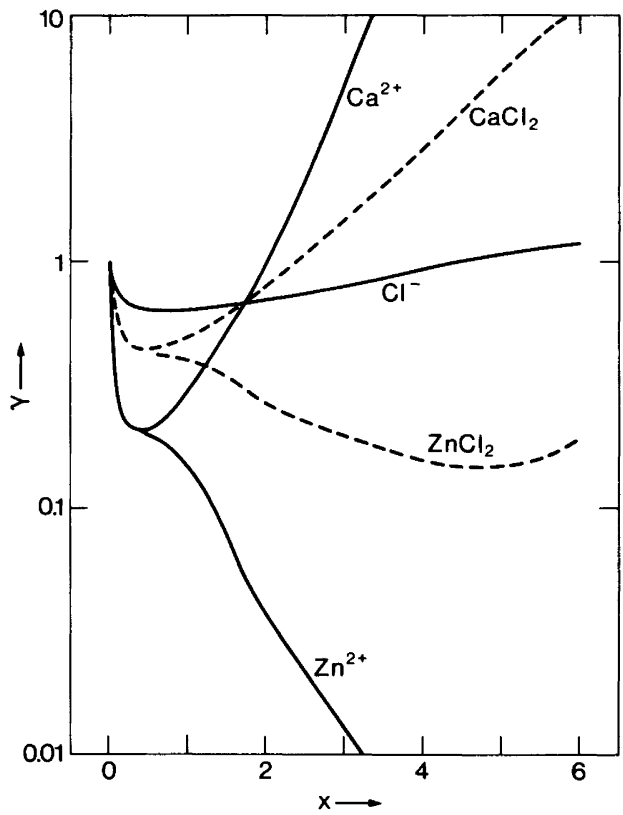

Fig. 1. Conventional mean-ion (dashed curves) and convenient single-ion (solid curves) activity coefficients in $0.005 \mathrm{~m} \mathrm{ZnCl}_{2}+x \mathrm{~m} \mathrm{CaCl}_{2}$ at $25^{\circ} \mathrm{C}$.
$\mathrm{Zn} / \mathrm{Zn}$ (II) electrode. Examples of Tafel data are given in Fig. 2.

With the reaction mechanism proposed, the Tafel lines should intersect at the reversible potential and twice the exchange current of the rate-determining $\mathrm{Zn}(\mathrm{I}) / \mathrm{Zn}(\mathrm{II})$ electron-transfer step. ${ }^{7,10}$ Table 3 gives values accordingly obtained for this exchange current $\left(i_{02}\right)$ mostly by extrapolating the more reproducible anodic Tafel lines to the reversible potential proper (Table 1). From ordinary electrode kinetics, ${ }^{7,10} i_{02}$ should depend on the bare-ion activity of zinc(II) by (when $\alpha_{2}=\frac{1}{2}$ ):

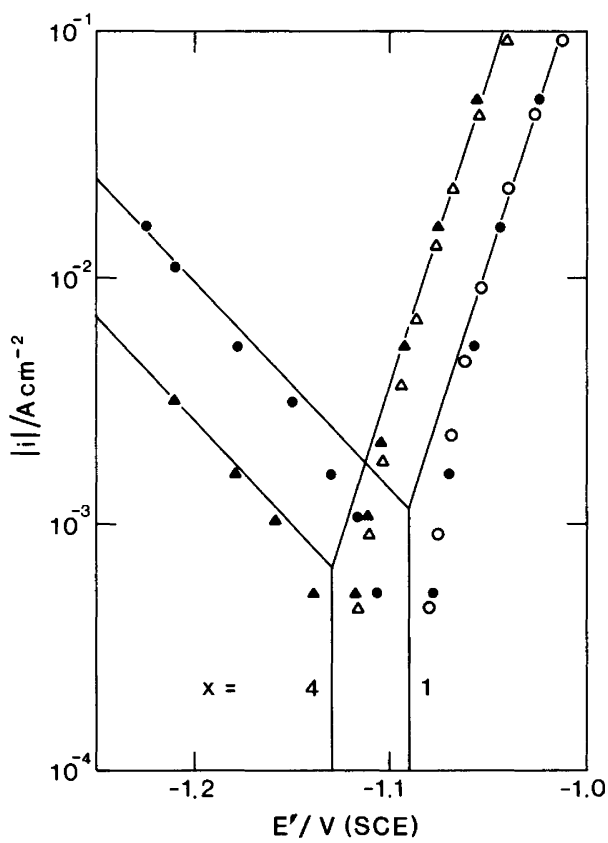

Fig. 2. Tafel data for solid zinc in acidified $(\mathrm{pH}$ near 2.5) $0.005 \mathrm{~m} \mathrm{ZnCl}_{2}+x \mathrm{~m} \mathrm{CaCl}_{2}$ for $x=1$ and 4 at $25{ }^{\circ} \mathrm{C}$ from (closed symbols) fast galvanostatic steps in unstirred solution and (open symbols) slow galvanostatic measurements in vigorously stirred solution. 
Table 3. Exchange data for $\mathrm{Zn}(\mathrm{I}) / \mathrm{Zn}(\mathrm{II})$ at solid zinc in $0.005 \mathrm{~m} \mathrm{ZnCl}{ }_{2}+x \mathrm{~m} \mathrm{CaCl}_{2}$ at $25^{\circ} \mathrm{C}$ (see text).

\begin{tabular}{llllllll}
\hline$x$ & 0.2 & 0.5 & 1 & 2 & 3 & 4 & 6 \\
\hline$i_{02} / \mathrm{mA} \mathrm{cm}^{-2}$ & 1.0 & 0.6 & 0.6 & 0.7 & 0.5 & 0.35 & 0.25 \\
$I_{02} / \mathrm{A} \mathrm{cm}^{-2}$ & 0.15 & 0.1 & 0.15 & 0.45 & 0.7 & 1.05 & 0.7 \\
\hline
\end{tabular}

$i_{02}=I_{02}\left(\gamma_{2}^{\prime}+m_{2+} / m^{\circ}\right)^{3 / 4}$

where the bare-zinc-ion standardized exchange rate $\left(I_{02}\right)$ still depends on ligand activities and doublelayer effects. Table 3 gives also values accordingly obtained for $I_{02}$ from $i_{02}$ and activity data (Table 2).

$I_{02}$ actually is a sum of terms, one term for each different $\mathrm{Zn}(\mathrm{I}) / \mathrm{Zn}$ (II) couple participating, and each term given by:

$I_{02, \mathrm{ij}}=I_{02, \mathrm{ij}}^{\circ}\left(\gamma_{-}^{\prime} m_{-} / m^{\circ}\right)^{i} a_{\mathrm{w}}{ }^{j}$

where $i$ and $j$ are the chloride and water ligand numbers of the couple concerned, and the further standardized exchange rate $\left(I_{02, \mathrm{ij}}^{\circ}\right)$ still depends on double-layer effects. Hence, $I_{02}$ should exhibit a simple chloride and water activity dependence only when determined predominantly by one of its terms, and then only if double-layer effects be small or nearly constant (or appropriately corrected for).

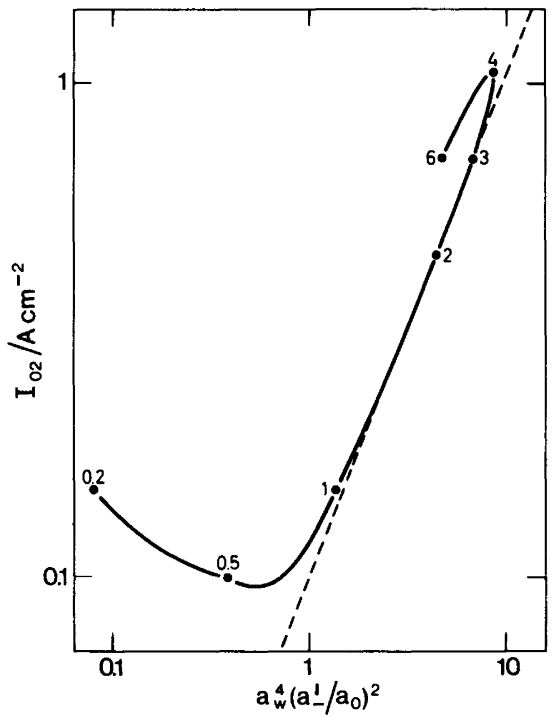

Fig. 3. Bare-zinc-ion standardized $\mathrm{Zn}(\mathrm{I}) / \mathrm{Zn}(\mathrm{II})$ exchange rate $I_{02}$ vs. $a_{\mathrm{w}}^{4}\left(\gamma_{-}^{\prime} m_{-} / m^{\circ}\right)^{2}$ for solid zinc in $0.005 \mathrm{~m} \mathrm{ZnCl}+x \mathrm{~m} \mathrm{CaCl}_{2}$ at $25^{\circ} \mathrm{C}$. Values of $x$ at the points.
In Fig. 3, the values obtained for $I_{02}$ (Table 3) are log-log plotted vs. $a_{\mathrm{w}}^{4}\left(\gamma_{-}^{\prime} m_{-} / m^{\circ}\right)^{2}$ for the solutions applied (Table 2). There a line of unit slope (dashed line) is nearly obeyed at $x$-values above 0.5 and is clearly disobeyed at lower $x$-values. This agrees with $\mathrm{Zn}\left(\mathrm{H}_{2} \mathrm{O}\right)_{4} \mathrm{Cl}_{2}^{-} / \mathrm{Zn}\left(\mathrm{H}_{2} \mathrm{O}\right)_{4} \mathrm{Cl}_{2}$ being the main electroactive $\mathrm{Zn}(\mathrm{I}) / \mathrm{Zn}(\mathrm{II})$ couple at $x$-values above 0.5 and with corresponding couples of lower or no chloride content taking control at lower $x$-values. ${ }^{1}$ Double-layer effects and the possible participation by higher chloride complexes are briefly considered in the Discussion below.

\section{DISCUSSION}

Although connected, the activity data and the kinetic data of the present work may appropriately be discussed separately.

Activities. Besides giving conventional mean-ion data for zinc chloride in various pure and mixed solutions with calcium chloride (Table 1), the present work yields convenient single-ion data for calcium chloride solutions with zinc chloride as a minority salt (Table 2 and Fig. 1). Even though the single-ion data to some extent depend on the validity of the values estimated and used for the liquid-junction potential difference $\left(\phi_{\mathrm{t}}-\phi_{\mathrm{r}}\right)$, and they hence are less certain than the mean-ion data, they certainly are more informative. Some information is extracted and used in the present kinetic studies, but more is held. It is hoped to treat this in a future more comprehensive analysis of convenient single-ion activity data.

Kinetics. The present results support the introductionally mentioned two-step charge-transfer mechanism of the $\mathrm{Zn} / \mathrm{Zn}$ (II) electrode (by the Tafel slopes observed) and its rate control by the $\mathrm{Zn}\left(\mathrm{H}_{2}\right)_{4} \mathrm{Cl}_{2}^{-} / \mathrm{Zn}\left(\mathrm{H}_{2} \mathrm{O}\right)_{4} \mathrm{Cl}_{2}$ couple over a large chloride concentration range (Fig. 3). The results of Fig. 3 further suggest that double-layer effects be rather small (or change rather little) under the experimental conditions, since larger deviations from a line of unit slope should otherwise have occurred. ${ }^{2}$ The slight deviations observed at high 
$x$-values may perhaps be due to a retarding diffuse-layer effect (by the Frumkin factor $\exp \left(\frac{1}{2} f \phi_{2}\right)$ with negative $\left.\phi_{2}\right)^{2}$ which decreases with increasing salt concentration (by $\left|\phi_{2}\right|$ then decreasing). These deviations, therefore, need not mean that $\mathrm{Zn}(\mathrm{I}) /-$ $\mathrm{Zn}(\mathrm{II})$ couples of higher chloride content come into account.

\section{REFERENCES}

1. Hurlen, T. and Fischer, K. P. J. Electroanal. Chem. 61 (1975) 165.

2. Hurlen, T. and Breivik, T. R. Acta Chem. Scand. 32 (1978) 447.

3. Hurlen, T. Electrochim. Acta 20 (1975) 499.

4. Ives, D. J. G. and Janz, G. J. Reference Electrodes, Academic, New York and London 1961.

5. Robinson, R. A. and Stokes, R. H. Electrolyte Solutions, 2nd Ed. (revised), Butterworths, London 1970.

6. Pourbaix, M. Atlas of Electrochemical Equilibria in Aqueous Solutions, Pergamon, Oxford 1966, p. 408.

7. Vetter, K. J. Electrochemical Kinetics, Academic, New York and London 1967.

8. Smith, R. M. and Martell, A. E. Critical Stability Constants, Vol. 4, Inorganic Complexes, Plenum, New York 1976, p. 108.

9. Skou, E., Jacobsen, T., van der Hoeven, W. and Atlung, S. Electrochim. Acta 22 (1977) 169.

10. Delahay, P.Double Layer and Electrode Kinetics, Interscience, New York 1965, p. 180.

Received May 9, 1978. 